\title{
Low-frequency components in harbor porpoise (Phocoena phocoena) clicks: communication signal, by-products, or artifacts?
}

\author{
M. Hansen ${ }^{\text {a) }}$ \\ Zoophysiology, Department of Biological Sciences, University of Aarhus, Denmark 8000 \\ M. Wahlberg \\ Fjord and Baelt, Margrethes Plads 1, 5300 Kerteminde, Denmark 8000 \\ P. T. Madsen \\ Zoophysiology, Department of Biological Sciences, University of Aarhus, Denmark and Woods Hole \\ Oceanographic Institution, Woods Hole, Massachusetts 02543
}

(Received 4 January 2008; revised 2 May 2008; accepted 19 May 2008)

\begin{abstract}
Underwater sound signals for biosonar and communication normally have different source properties to serve the purposes of generating efficient acoustic backscatter from small objects or conveying information to conspecifics. Harbor porpoises (Phocoena phocoena) are nonwhistling toothed whales that produce directional, narrowband, high-frequency (HF) echolocation clicks. This study tests the hypothesis that their $130 \mathrm{kHz}$ HF clicks also contain a low-frequency (LF) component more suited for communication. Clicks from three captive porpoises were analyzed to quantify the LF and HF source properties. The LF component is 59 (S.E.M $=1.45 \mathrm{~dB}$ ) dB lower than the HF component recorded on axis, and even at extreme off-axis angles of up to $135^{\circ}$, the HF component is $9 \mathrm{~dB}$ higher than the LF component. Consequently, the active space of the HF component will always be larger than that of the LF component. It is concluded that the LF component is a by-product of the sound generator rather than a dedicated pulse produced to serve communication purposes. It is demonstrated that distortion and clipping in analog tape recorders can explain some of the prominent LF components reported in earlier studies, emphasizing the risk of erroneous classification of sound types based on recording artifacts.
\end{abstract}

(C) 2008 Acoustical Society of America. [DOI: 10.1121/1.2945154]

PACS number(s): 43.80.Ka [WWA]

Pages: $4059-4068$

\section{INTRODUCTION}

Water offers a series of options and constraints as a medium for transmitting stimuli to the sensory systems of aquatic animals (Dusenbery, 1992). Compared to other sensory cues such as light, sound travels with little attenuation in water and is therefore used by a large number of marine organisms to acquire and communicate information (Tyack and Clark, 2000). Toothed whales have evolved the capability to use sound for both passive listening, communication, and echolocation (biosonar) where objects are actively probed with sound (Tyack, 1998).

Sounds used for communication are often emitted at wavelengths positively correlated with the size of the animal emitting them (Fletcher, 2004). This relationship may be explained by the fact that sound production efficiency and directionality are dependent on the ratio between the size of the sound producing structures and the emitted wavelengths. Thus, with respect to the transmitting structures, long wavelengths lead to a low radiation directionality that increases the possibility of being heard by conspecifics (and predators) (Bradbury and Vehrencamp, 1998). However, a low radiation

\footnotetext{
${ }^{a)}$ Electronic mail: michael_hansen@biology.au.dk
}

directionality is not suitable for biosonar signals that must be collimated to reduce clutter and achieve high source levels (SLs) (Au, 1993). Echolocating toothed whales are thus faced with an apparent need for high-frequency (HF) signals for effective echolocation of small prey items, and possibly more low-frequency (LF) signals for communication. Such a bimodal sound production is seen in most delphinids that produce frequency modulated whistles with fundamental frequencies in the $5-30 \mathrm{kHz}$ range for communication (Lammers et al., 2003; Janik, 2005) and very short clicks at centroid frequencies between 30 and $120 \mathrm{kHz}$ for echolocation (Au, 1993). Other toothed whale species, such as the sperm whale, have a sound repertoire almost exclusively made up of clicks, but with properties apparently serving the different purposes of communication and echolocation (Madsen et al., 2002a). Sperm whale usual sonar clicks consist of a weak LF component suited for communication (Zimmer et al., 2005a) and a HF component of very high SL and directionality (Mohl et al., 2003) suited for long-range echolocation of mesopelagic prey (Madsen et al., 2002a). Sperm whales also produce so-called coda clicks and slow clicks in the context of social interactions with lower centroid frequencies and SLs, and most likely broader radiation patterns (Madsen et al., 2002a, 2002b). 
Even though many toothed whales produce both HF sonar clicks and LF communication signals, some toothed whale species only seem to produce ultrasonic clicks with properties suited for biosonar. Members of the families Phocoenidae and Kogidae and the genus Cephalorhyncus belong to the group of toothed whales that produce narrowband high-frequency (NBHF) clicks (Au, 1997) with centroid frequencies above $100 \mathrm{kHz}$ and high $Q$ 's (centroid frequency divided by half power band width) (Madsen et al., 2005).

It remains at present unclear why these unrelated toothed whale species living in different habitats have converged evolutionary to produce essentially identical NBHF clicks. Most of these species are small and therefore need very short wavelengths to achieve sufficient directionality in their biosonar systems. Mohl and Andersen (1973) suggested that NBHF clicks could be an adaptation to the low ambient noise window around $130 \mathrm{kHz}$ (Madsen et al., 2005). Several authors (Andersen and Amundin, 1976; Madsen et al., 2005; Morisaka and Connor, 2007) have also advanced the hypothesis that the evolution of NBHF clicks may have been driven by killer whale predation, as NBHF clicks are produced beyond the upper hearing limit of these apex predators (Szymanski et al., 1999).

Second, these nonwhistling toothed whales apparently do not emit signals of lower frequency and directionality as most delphinids for communication purposes. However, if porpoise clicks like sperm whale clicks (Zimmer et al., 2005b) carry a LF component of low directionality, it can be envisioned that the HF component of the NBHF click is used for echolocation and the LF component for communication (Mohl and Andersen, 1973). In fact, porpoise sounds were first described by Schevill et al. (1969) as narrowband, lowlevel clicks with a peak frequency around $2 \mathrm{kHz}$, a duration between 0.5 and $5 \mathrm{~ms}$, and SLs around $100 \mathrm{~dB}$ re $1 \mu \mathrm{Pa}$ (measure of reference unknown) at $1 \mathrm{~m}$. However, a frequency of $2 \mathrm{kHz}$ corresponds to a wavelength of $0.75 \mathrm{~m}$, which is inconsistent with the animal's ability to echolocate wires with a diameter of only $0.5 \mathrm{~mm}$ that only reflects sound efficiently at much higher frequencies. Dubrovskii (1971) investigated harbor porpoises ability to make sounds at higher frequencies and found that they produced clicks at frequencies up to at least $100 \mathrm{kHz}$. In 1973, Mohl and Andersen reported porpoise clicks to have the bulk part of their energy concentrated between 100 and $160 \mathrm{kHz}$ and SLs of $140-160 \mathrm{~dB}$ re $1 \mu \mathrm{Pa}_{\text {(peak) }}$. They further noted the presence of a much weaker $(<-50 \mathrm{~dB}) \mathrm{LF}$ component around $2 \mathrm{kHz}$ produced along with the $\mathrm{HF}$ component around $130 \mathrm{kHz}$ (Mohl and Andersen, 1973; Amundin, 1991).

In addition to this, Kamminga and Wiersma (1981) described a $20 \mathrm{kHz}$ component in porpoise clicks, and Verboom and Kastelein $(1995,1997)$ classified additional frequency components at 30 and $60 \mathrm{kHz}$ as well as broad band components between 13 and $100 \mathrm{kHz}$. Thus, many alternative frequency components other than the dominating $130 \mathrm{kHz}$ component has been reported for harbor porpoise clicks.

Here, we quantify the broadband source properties of harbor porpoise clicks to test the hypothesis that they have dedicated HF and LF components suited for the dual pur- poses of echolocation and communication. We show that porpoise clicks indeed contain a very weak LF component around $2 \mathrm{kHz}$, but that the HF component has significantly more energy irrespective of the recording aspect. It is also demonstrated that analog tape recorders can generate LF artifacts that can lead to erroneous classification and artifactual functional conclusions when analyzing toothed whale clicks.

\section{MATERIALS AND METHODS}

\section{A. Far-range recordings of free-swimming porpoises}

Several thousand clicks were recorded from three porpoises at Fjord \& Belt, Kerteminde, Denmark, in a seminatural outdoor enclosure with a size of about $35 \times 15 \mathrm{~m}^{2}$. Three captive porpoises were used in the study: a ten-year-old male called Eigil, an eleven-year-old female called Freja, and the three-year-old female, Sif. All animals were brought to Fjord $\&$ Belt after being accidentally caught in pound nets to study methods for reducing bycatch of porpoises. A calibrated Reson TC4014 hydrophone with a sensitivity of $-187 \mathrm{~dB}$ re $1 \mathrm{~V} / \mu \mathrm{Pa}( \pm 2 \mathrm{~dB})$ between 0.5 and $180 \mathrm{kHz}$ was deployed at $1 \mathrm{~m}$ depth. The animals were allowed to swim freely and approach the hydrophone while clicking. The signal from the hydrophone was split into two channels and digitized on a 16 bit National Instruments (NI) USB-6251 DAQ card sampling at $500 \mathrm{kHz}$. Both channels were bandpass filtered between $0.1 \mathrm{kHz}$ (first order) and $150 \mathrm{kHz}$ (eight order) and amplified by 40 and $60 \mathrm{~dB}$, respectively, thereby increasing the dynamic range of the recording setup.

Clicks with a broadband signal-to-noise ratio (SNR) of at least $10 \mathrm{~dB}$ were extracted in a $10 \mathrm{~ms}$ window symmetric around the peak of the signal envelope using a customwritten click detector in MATLAB 7.0.1 (The MathWorks, Inc.). Each extracted click window was then analyzed for $\mathrm{HF}$ and LF components. For the HF content, the click was bandpass filtered with fourth order Butterworth low- and high-pass filters with corner frequencies $(-3 \mathrm{~dB})$ at 100 and $160 \mathrm{kHz}$. For the LF content, the corner frequencies of the bandpass filter $(2 \times 4$ order $)$ were set at 0.5 and $5 \mathrm{kHz}$.

The received rms level $\left(\mathrm{RL}_{\mathrm{rms}}\right)$ of the LF and HF components were computed in a $2 \mathrm{~ms}$ window. A $5 \mathrm{~ms}$ window was extracted $5 \mathrm{~ms}$ before and after the click window, and the $\mathrm{RL}_{\mathrm{rms}}$ of the three windows were calculated. The rms noise level before the click was then subtracted from the signal rms value in order to calculate the in-band SNR (signal residual) for both the HF and the LF signals. Next, we subtracted the noise rms value before the click from the noise rms value after the click to get a measure of the noise variation around the clicks (noise residual).

Click series each containing 50-200 clicks with a broadband SNR of more than $10 \mathrm{~dB}$ were extracted using a custom written MATLAB script (courtesy K. Beedholm). To improve the SNR, the clicks were phase aligned based on the HF component, and then averaged and subsequently bandpass filtered at $100-160 \mathrm{kHz}$ and at $0.5-5 \mathrm{kHz}$.

\section{B. Close-range recordings}

The far-field recordings of individual clicks did not reveal any LF component in spite of the large dynamic range 
of the recording equipment. This indicates that the LF component, if present, must have been masked by the background noise. To improve the SNR, we set up a close-range recording experiment. The study was conducted at the Fjord $\&$ Belt Centre on each of the three animals. The B\&K 8101 hydrophone used in the experiment had a flat sensitivity of $-184 \mathrm{~dB}$ re $1 \mathrm{~V} / \mu \mathrm{Pa}( \pm 2 \mathrm{~dB})$ in the frequency range of $0.1 \mathrm{~Hz}-70 \mathrm{kHz}$. At higher frequencies, the sensitivity drops and the receiving beam pattern is no longer omnidirectional. To compensate for this, the hydrophone was calibrated at $130 \mathrm{kHz}$ relative to a Reson TC 4034, with a sensitivity of $-220 \mathrm{~dB}$ re $1 \mathrm{~V} / \mu \mathrm{Pa}$ at $130 \mathrm{kHz}$ in an anechoic tank. The sensitivity of the $\mathrm{B} \& \mathrm{~K} 8101$ in the horizontal plane was measured to be $-193 \mathrm{~dB}$ re $1 \mathrm{~V} / \mu \mathrm{Pa}$ at $130 \mathrm{kHz}$ matching the calibration charts in the $\mathrm{B} \& \mathrm{~K}$ manual. The hydrophone was held on what was assumed to be the acoustic axis of the animal at a distance of $27 \mathrm{~cm}$ from the melon. The signals were bandpass filtered at $0.1-150 \mathrm{kHz}$ (first and eight orders, respectively) and amplified by 40 or $50 \mathrm{~dB}$ before digitization using the 16 bit NI recorder sampling at $500 \mathrm{kHz}$.

\section{Radiation beam pattern of high-frequency components}

To estimate the active space ${ }^{1}$ of the directional HF component, we set up an experiment to measure the beam pattern at larger off-axis angles than measured by Au et al. (1999).

The experiment was conducted during two sessions at Fjord \& Belt. The male porpoise Eigil was trained to dive down and station on a plate at a depth of $1.5 \mathrm{~m}$ and echolocate. Four Reson TC 4034 hydrophones was mounted on a $Y$-shaped hydrophone array (Rasmussen et al., 2002) with a distance of $45 \mathrm{~cm}$ between the center and the outer hydrophones. The array was placed $2.4 \mathrm{~m}$ in front of the porpoise with the center hydrophone at the same depth as the animal. The signals from the array hydrophones were bandpass filtered from $1-200 \mathrm{kHz}$ and amplified $60 \mathrm{~dB}$ before digitization with a custom built 12 bit ADC sampling at $500 \mathrm{kHz}$. The signal from the center hydrophone was split into two channels, and one of them was relayed to a second digital recording system to maintain synchronization.

To the right side of the animal, three B\&K 8101 hydrophones were suspended at $45^{\circ}, 90^{\circ}$, and $135^{\circ}$ relative to the body axis of the clicking animal. Together with the relayed signal from the centre hydrophone of the $Y$-shaped array, the signals from the three 8101 hydrophones were bandpass filtered from $100 \mathrm{~Hz}$ to $150 \mathrm{kHz}$, amplified by $50 \mathrm{~dB}$ and recorded with the 16 bit NI recorder sampling at $500 \mathrm{kHz}$.

The recordings were analyzed with custom written scripts in MATLAB. Due to the very narrow beam pattern of the porpoise, it is crucial only to use on-axis clicks when calculating the SL from which the directionality of off-axis clicks is defined (Madsen and Wahlberg, 2007). To ensure analysis of on-axis clicks only, a criterion was defined from the beam pattern data of Au et al. (1999) specifying that the received level (RL) at the center hydrophone should be at least $3 \mathrm{~dB}$ above the RL at any of the outer hydrophones in the $Y$-array recordings. For the levels in $\mathrm{dB}$ re $1 \mu \mathrm{Pa}_{(\mathrm{pp})}$ referred to $1 \mathrm{~m}$ for the off-axis versions of the clicks, we use the term apparent source level (ASL), which is the backcalculated sound pressure level to $1 \mathrm{~m}$ of a directional sound source measured off the acoustic axis (Mohl et al., 2000) When a click fulfilled the on-axis criterion, the same click was located in the off-axis recordings, and their ASLs were computed for each of the three angles.

\section{Comparing analog to digital recordings}

The effective dynamic range of an analog tape recorder is more than $40 \mathrm{~dB}$ (100 times) lower than that of a 16 bit digital recorder. Due to the large difference in sound pressure of the HF and LF component (Amundin, 1991a), an analog tape recorder should not be able to record both components on the acoustic axis of the HF component on the same channel without distortion. It can therefore be hypothesized that the often prominent LF component reported from older studies using analog tape recorders could at least in part be an artifact generated by analog recording systems, as outlined by Diercks et al. (1973). To test this hypothesis, we made recordings of clicks from free-swimming porpoises using a Reson TC4014 hydrophone connected to both a digital and an analog recorder via a $40 \mathrm{~dB}$ gain box with a first order high-pass filter at $100 \mathrm{~Hz}$ and an eight order $150 \mathrm{kHz}$ antialiasing filter. The signal from the amplifier was split into two channels. One channel was connected to a 12 bit IO-tech Wavebook with a clip level of $2 \mathrm{~V}_{\mathrm{pp}}$ and a sampling rate of $500 \mathrm{kHz}$. The other channel was connected to a Lyrec TR-47 analog tape recorder [used by Mohl and Andersen (1973)] set at $0.1 \mathrm{~V}_{\mathrm{pp}}$ clip level, corresponding to a maximum recordable received level of $146 \mathrm{~dB}$ re $1 \mu \mathrm{Pa}_{\mathrm{pp}}$. The tape speed was set to $30 \mathrm{in} . / \mathrm{s}$, providing an effective recording bandwidth of $150 \mathrm{kHz}$. The analog recordings were later digitized using a 12 bit AD-link ADC sampling at $500 \mathrm{kHz}$. Finally, the digital recordings from the Wavebook and the digitized analog recordings were aligned in stereo files to compare the same clicks recorded by the two sets of recording gear.

A click with amplitude below clip level of the tape recorder was picked from the digital recording and analyzed for its frequency content. The same click from the digitized analog recordings was extracted to compare the frequency content from each recording by means of power spectra with a fast Fourier transform (FFT) size of 256 on rectangular windowed data. Next, we picked a click that was clipped from the digitized analog recordings and compared its frequency content to the same click in the digitized recording that was not clipped. We calculated the in-band SNR as well as the ratio between the noise windows before and after the signal window for 13 clicks above the clipping level of the tape recorder in the $0.5-5 \mathrm{kHz}$ band as in experiment 1 . Finally, we performed a Wilcoxon signed rank test on the 13 clicks to test if the signal residuals and noise residuals were significantly different from zero and hence contained any significant LF energy.

\section{E. Recording of artificial porpoise clicks}

To test if pure tone HF pulses can generate LF artifacts in analog tape recorders, we recorded artificial HF pulses at different levels on two different tape recorders, a Lyrec and a 
Nagra tape recorder. Burst pulses consisting of 15 cycles at $125 \mathrm{kHz}$ and a repetition rate of $66 \mathrm{~Hz}$ were created using an Agilent 33220A Arbitrary Waveform Generator. The signal was filtered through a B\&K 1614 analog 1/3-octave filter set at a center frequency of $125 \mathrm{kHz}$, producing clicks that closely mimic porpoise clicks [Fig. 6(A)]. The signals were recorded on a Lyrec TR 47-3 tape recorder set at $2 \mathrm{~V}_{\mathrm{pp}}$ clip level and $30 \mathrm{in./s}$ tape speed (used by Mohl and Andersen, 1973). Four input levels of $1,2,4$, and $8 \mathrm{~V}_{\mathrm{pp}}$ were recorded. The analog tape recordings were subsequently digitized with a 12 bit AD-link ADC sampling at $500 \mathrm{kHz}$ set at $10 \mathrm{~V}_{\mathrm{pp}}$ clip level.

The recording of artificial porpoise clicks was repeated with a Nagra IV-D tape recorder at $15 \mathrm{in./s}$ [used by Amundin, 1991a; 1991b) to record LF components of porpoise clicks]. Theoretically, this should provide a frequency response up to $75 \mathrm{kHz}$, but according to the specifications, the frequency response is limited to $16 \mathrm{kHz}$. The tape recorder was set to a clip level of $3 \mathrm{~V}_{\mathrm{pp}}$. Four input levels were recorded at 1.5, 3, 6, and $12 \mathrm{~V}_{\mathrm{pp}}$ and digitized as above. The frequency content of the four input levels was compared in each of the experiments by means of power spectra with a FFT size of 256 on rectangular windowed data.

\section{RESULTS AND DISCUSSION}

Echolocating toothed whales emit directional and highpowered clicks to achieve sufficient echo to noise/clutter levels when engaged in biosonar-based foraging ( $\mathrm{Au}, 1993)$. Many toothed whales therefore produce LF whistles or burst pulses to increase their active space with signals of low directionality (Tyack, 1998). Here, we conducted a series of experiments to test the hypothesis that the reported LF component of porpoise clicks has source properties suited for communication.

\section{A. Recordings of free-swimming porpoises}

Early papers by Schevill et al. (1969), Mohl and Andersen (1973), Amundin (1991b), and Verboom and Kastelein (1995) all reported a prominent LF component in porpoise clicks. Yet, recent papers on porpoise clicks (Au et al., 1999; Kastelein et al., 1999; Teilmann et al., 2002; Villadsgaard et al., 2006) have not reported any LF component, and we have not previously noticed a LF component from recordings with digital recording gear. The use of high-pass filters or masking by ambient LF noise can easily explain why the LF component could go unnoticed, but it is suggested that the LF component, if present, must be weak (Amundin, 1991a).

In order to quantify the LF component along with the powerful HF component, we used a 16 bit digital recording system with a theoretical dynamic range of $96 \mathrm{~dB}$. This should be sufficient to handle the $40-60 \mathrm{~dB}$ difference in sound pressure of the two components reported by Mohl and Andersen (1973). We deployed a single, HF, low-noise hydrophone (Reson TC 4014) in a large net pen with three porpoises engaged in different types of behavior including social interactions. More than $2 \frac{1}{2} \mathrm{~h}$ of recordings were made from different click trains from all three animals containing a total of some 1000 clicks with a broadband SNR of more
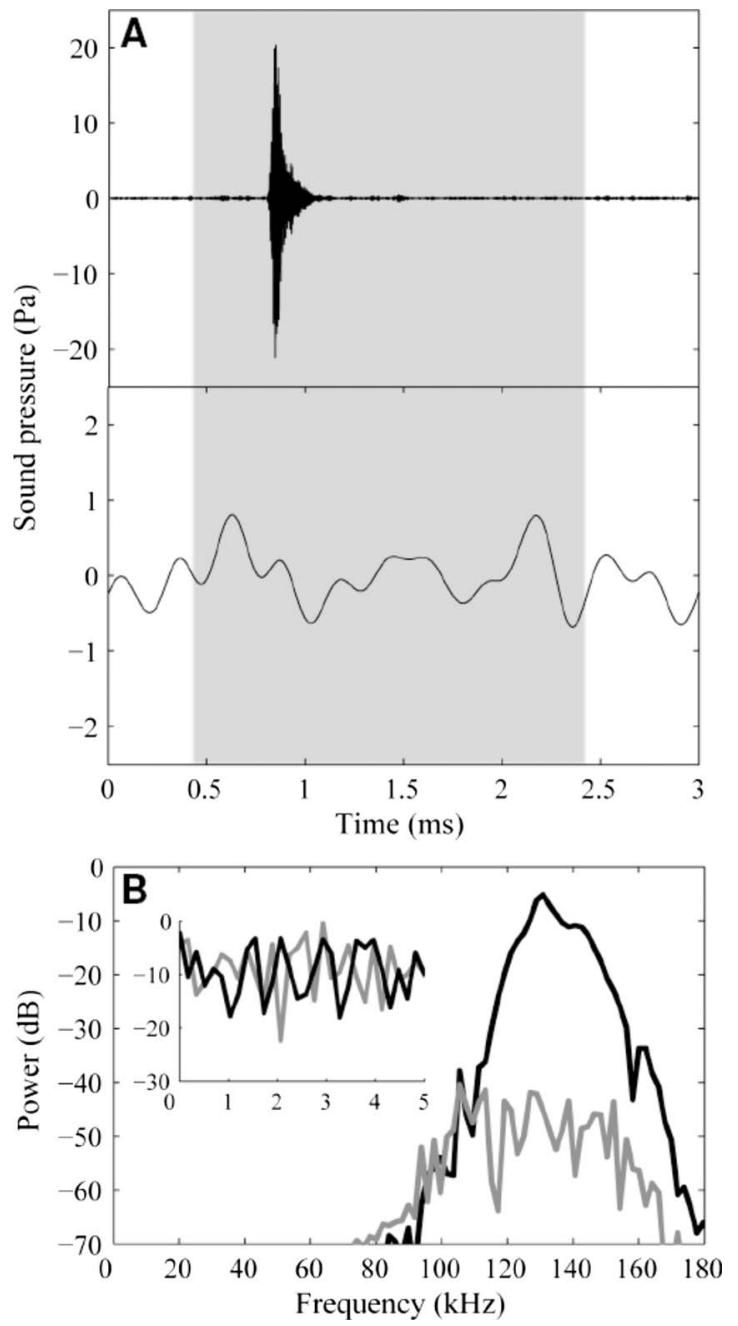

FIG. 1. (A) Waveform of a click from a free-swimming porpoise, bandpass filtered between 100 and $160 \mathrm{kHz}$ (top) and between 0.5 and $5 \mathrm{kHz}$ (bottom). The gray area marks the $2 \mathrm{~ms}$ signal window used in the data analysis. The noise windows are located $5 \mathrm{~ms}$ before the beginning of the gray area and $5 \mathrm{~ms}$ after the ending of it. (B) Power spectra of the HF filtered $(100-160 \mathrm{kHz})$ and $\mathrm{LF}$ filtered $[0.5-5 \mathrm{kHz}$ (insert)] frequency content of the click (black curve) and the noise window (gray curve) $5 \mathrm{~ms}$ before the click window. FFT size of 256, rectangular windowed data, sampling frequency of $500 \mathrm{kHz}$.

than $10 \mathrm{~dB}$. Figure 1(A) shows the waveform of the HF component (top) of the most powerful click in one of the recorded click trains, filtered between 100 and $160 \mathrm{kHz}$, and the waveform of the same click filtered between 0.5 and $5 \mathrm{kHz}$ (bottom). It is seen that no LF component is apparent above the background noise, and we could not identify any LF components by simple bandpass filtering in any of the clicks recorded this way despite the large dynamic range of the recording chain [Fig. 1(B)].

However, a missing LF component in the few $(<100)$ clicks analyzed individually from the recordings may be explained by the possibility that the animals may have different click types (Verboom and Kastelein, 1995; 1997) and that we by chance did not analyze any clicks containing LF components. Using a custom written click extractor in MATLAB, analysis was therefore performed on more than 1000 clicks recorded from the three animals to test for significant LF 

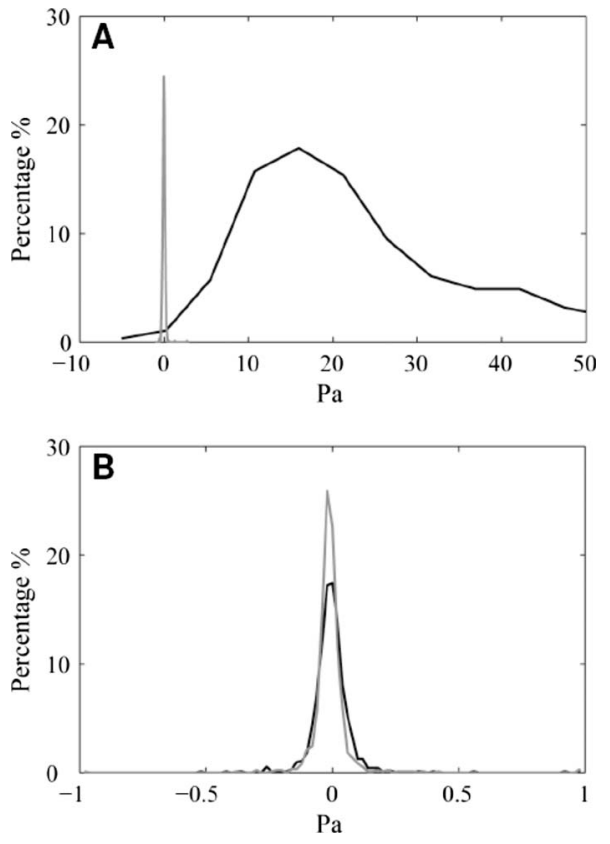

FIG. 2. Histograms of the signal (black curve) and noise residuals (gray curve) from the far-range recordings $(n=1000)$. (A) is bandpass filtered between 100 and $160 \mathrm{kHz}$ (binwidth of $20 \mathrm{mPa}$ ) and (B) bandpass filtered between 0.5 and $5 \mathrm{kHz}$ (binwidth of $5.24 \mathrm{~Pa}$ for the signal residual and $80 \mathrm{mPa}$ for the noise residual).

energy in clicks emitted in a range of different behavioral settings including foraging and socializing.

When subtracting the rms noise level in a $5 \mathrm{~ms}$ noise window before the click from the rms noise level of a $5 \mathrm{~ms}$ noise window after the click, the mean value is as expected distributed around $0 \mathrm{~Pa}$ for both the $0.5-5 \mathrm{kHz}$ and $100-160 \mathrm{kHz}$ bands [Figs. 2(A) and 2(A)]. Subtracting the rms noise level before the click from the rms pressure of a 2 ms window around the click, we get a noise-corrected HF component rms pressure with a median of $24 \mathrm{~Pa}_{(\mathrm{rms})}$ (ranging from -3 to $256 \mathrm{~Pa})^{2}$ sound pressure in the 100 and $160 \mathrm{kHz}$ band [Fig. 2(A)]. Unsurprisingly, we thus demonstrate a strong HF component [Fig. 2(A)] with received rms levels computed over a $2 \mathrm{~ms}$ long window up to $168 \mathrm{~dB}$ re $1 \mu \mathrm{Pa}_{\text {(rms) }}$. When doing the same for the $0.5-5 \mathrm{kHz}$ band, the mean is distributed around zero [Fig. 2(B)]. No LF component can therefore be found under the ambient noise conditions (70-80 dB re $1 \mu \mathrm{Pa}$ in the 1/3-octave band around $2 \mathrm{kHz})$ given for the 1000 clicks recorded from the freeranging porpoises at ranges from 1 to $20 \mathrm{~m}$ with broadband received levels between 144 and $180 \mathrm{~dB}$ re $\mu \mathrm{Pa}_{\mathrm{pp}}$. Detection of the LF component may thus have been masked by the background noise in the enclosure.

If we instead ran a click detector in combination with phase-aligned click averaging, the improved SNR revealed a very weak LF component detectable some $50-60 \mathrm{~dB}_{\mathrm{pp}}$ below the level of the HF component.

\section{B. Close-range recordings of porpoise clicks}

To improve the SNR and quantify the click properties of each animal, we reduced the distance from the animal to the hydrophone by stationing the animal and making it echolo- cate on a B\&K 8101 hydrophone $27 \mathrm{~cm}$ in front of it. More than a thousand clicks were recorded from each of the three animals. A LF component could still not be detected in the frequency band from $0.5-5 \mathrm{kHz}$ when analyzing single clicks through bandpass filtering and inspection of the waveform. Using again a click detector and phase-aligned averaging to improve the SNR, we could demonstrate a clear LF component in click trains from all three animals (Fig. 3). It consists of roughly 2 cycles at a peak frequency of $\sim 2 \mathrm{kHz}$ for all three animals (Table I). The differences in peak-peak source levels of 48-68 dB between the two components lie within the ranges reported earlier (Mohl and Andersen, 1973; Amundin, 1991b). A genuine, though very weak LF component is thus verified in porpoise echolocation clicks.

\section{Radiation beam pattern of high-frequency components}

Recorded on axis, the ASL of the HF component will always be higher than the LF component by at least some $50 \mathrm{~dB}$ (Table I), and the question is if that is also the case off axis. The high directionality of the HF component renders very little HF signal energy off axis (Au et al., 1999) and it is conceivable that the LF component will be stronger in off-axis aspects and therefore serve the purpose of communication in off-axis aspects, as suggested by Mohl and Andersen (1973).

To investigate this, we measured the beam pattern for the HF component to compare the active space of the HF and LF components in porpoise clicks. Fourteen clicks out of approximately 2000 clicks passed the criteria for being recorded on the acoustic axis. The HF component was detectable at all three off-axis aspects measured. The off-axis ASLs were on average reduced by $27 \mathrm{~dB}( \pm 5 \mathrm{~dB}$ std. dev. $)$ at the $45^{\circ}$ position, by $37 \mathrm{~dB}$ at the $90^{\circ}$ position and $44 \mathrm{~dB}$ at the $135^{\circ}$ position (Fig. 4). Assuming that the beam pattern is symmetrical around the acoustic axis, the data have been mirrored to cover both sides of the animal. Furthermore, Fig. 4 depicts the likely radiation of the LF component that can be assumed to have a low if any directionality given the long wavelength and the relatively small transmitting aperture of a porpoise head (Au et al., 1999). Figure 4 demonstrates that the ASL of the LF component is always weaker than the HF component irrespective of aspect to the clicking animal, which could lead to the premature conclusion that the LF component can be ignored altogether from a communication standpoint. However, the two components suffer very differently from absorption and must be detected by listening porpoises at very different ambient noise levels.

To be detected, a signal must have a sufficient SNR at the receiver, and the detection of a signal is therefore limited by the ambient noise or the hearing threshold of the animal. In the following, we assume that a signal is detectable when the received signal level matches the hearing threshold at the given frequency or the ambient noise third octave band level (TOL) at that frequency if the noise TOL is higher than the hearing threshold. In our case, the relevant center frequencies are 2 and $125 \mathrm{kHz}$ for the LF and HF components, respectively. The audiogram of a porpoise has been measured by Kastelein et al. (2002) showing that the mean hearing thresh- 

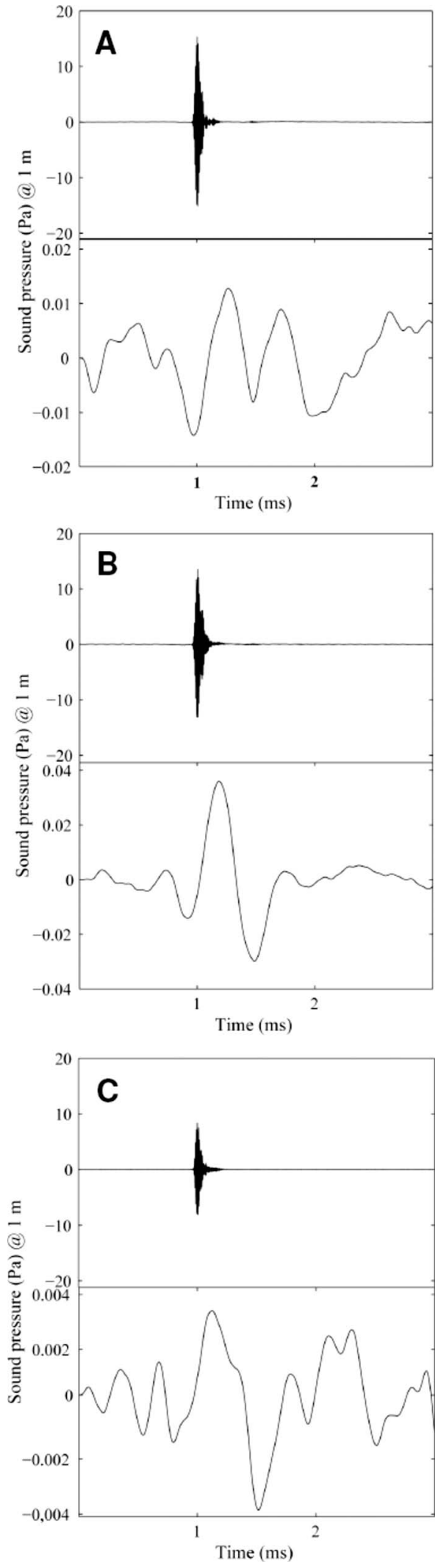

FIG. 3. Waveforms of the HF (top panel) and LF content (bottom panel) from Sif (A), Freja (B), and Eigil (C), after averaging $>25$ clicks to improve the SNR.

old at $2 \mathrm{kHz}$ is $72 \mathrm{~dB}$ re $1 \mu \mathrm{Pa}_{(\mathrm{rms})}$. With an ambient noise TOL at $2 \mathrm{kHz}$ of some $80 \mathrm{~dB}$ re $1 \mu \mathrm{Pa}_{\text {(rms) }}$ (comparable to the levels measured in the present experiment) at a wind speed of $5 \mathrm{~m} \mathrm{~s}^{-1}$ (Piggott, 1964), it seems reasonable to assume that ambient noise is often limiting detection of $2 \mathrm{kHz}$ pulses. With the SLs and detection thresholds defined, we can estimate the detection ranges of the HF and LF components using the passive sonar equation (Urick, 1983).

The mean SL of $86 \mathrm{~dB}$ re $1 \mu \mathrm{Pa}_{\mathrm{pp}}$ renders rms sound pressure levels that are so low relative to the ambient TOL at $2 \mathrm{kHz}$ that porpoises will have to be very close to detect the LF component under prevailing ambient noise levels in shallow water. Even the highest measured LF SL of $97 \mathrm{~dB}$ re $1 \mu \mathrm{Pa}_{\mathrm{pp}}$ [comparable to the $100 \mathrm{~dB}$ re $1 \mu \mathrm{Pa}$ reported by Schevill et al. (1969)] only leaves an active space of 2-3 m based on the passive sonar equation. It is therefore clear that our findings do not support the hypothesis that the LF components can serve as a useful vehicle for LF, omnidirectional communication in porpoises instead of the HF component.

The energy flux density detection threshold for the $130 \mathrm{kHz}$ component lies between 22.4 and $27.4 \mathrm{~dB}$ re $1 \mu \mathrm{Pa}^{2} \mathrm{~s}$ when the animal is pointing toward the sound source, ( $0^{\circ}$ aspect) (Kastelein et al., 1999). If the animal is pointing away $\left(180^{\circ}\right.$ aspect) from the sound source, the threshold is likely to be raised by at least $11.7 \mathrm{~dB}$ (at $100 \mathrm{kHz})$ due to the lack of gain from directional hearing (Kastelein et al., 2005). The source energy flux density of porpoise clicks can be estimated from their pp sound pressure SL by subtracting $51 \mathrm{~dB}$ (Kastelein et al., 1999). Assuming spherical spreading and an absorption of $0.04 \mathrm{~dB}$ m (Villadsgaard et al., 2006) and that the DI at $130 \mathrm{kHz}$ is the same as for $100 \mathrm{kHz}$, we estimated the detection range for the $0^{\circ}$ and $180^{\circ}$ listening aspects for each of the five angles of the beam pattern at three different SLs of 200, 180, and $160 \mathrm{~dB}$ re $1 \mu \mathrm{Pa}_{\mathrm{pp}}$ (Villadsgaard et al., 2006), using a $27.4 \mathrm{~dB}$ re $1 \mu \mathrm{Pa}^{2}$ s detection threshold (Fig. 5). Compared to other toothed whales, these SLs are low and the absorption is very high which leads to short detection ranges. The maximum range at which the clicking animal could be detected by conspecifics under the above assumptions is some $1500 \mathrm{~m}$ at a SL of $200 \mathrm{~dB}$ re $1 \mu \mathrm{Pa}_{\mathrm{pp}}$ in $0^{\circ}$ listening aspect (Fig. 5). A SL of $160 \mathrm{~dB}$ re $1 \mu \mathrm{Pa}_{\mathrm{pp}}$ renders a detection range of around $670 \mathrm{~m}$, in the on-axis direction. Due to the high directionality of the HF component, porpoises are likely to face much shorter detection ranges in daily life. Off axis at $135^{\circ}$, the range is reduced to about $600 \mathrm{~m}$ for the highest SL, while it is only $60 \mathrm{~m}$ for the off-axis version of a click with a SL of $160 \mathrm{~dB}$ re $1 \mu \mathrm{Pa}_{\mathrm{pp}}$.

The HF will despite the relatively short detection ranges always be more dominant compared to the LF and generate the largest active space irrespective of listening aspect to the clicking animal, and the LF component will therefore most likely not play any significant role in acoustic communication of porpoises.

The harbor porpoise is an example of a toothed whale with a small active space that does not fit into the general trend that sounds for communication are of LF and omnidirectional nature (Bradbury and Vehrencamp, 1998). The short communication ranges of some $50-1500 \mathrm{~m}$ in porpoises testify that these nongregarious animals, which often travel alone or in small groups, indeed have a limited capability to acoustically locate and communicate with conspe- 
TABLE I. Source characteristics for each of the three animals measured in the close range recordings. (SLs) are brackcalculated to $1 \mathrm{~m}$ from estimated on axis measurements at $0.27 \mathrm{~m}$.

\begin{tabular}{lcccccc}
\hline \hline & $\begin{array}{c}\text { Number of } \\
\text { click trains } \\
\text { averaged }\end{array}$ & $\begin{array}{c}\text { HF SL } \\
(\min / \max )\end{array}$ & $\begin{array}{c}\text { HF SL } \\
(\min / \max ) \\
\mathrm{dB} \text { re } 1 \mu \mathrm{Pa}_{\text {p.p. }}\end{array}$ & $\begin{array}{c}\text { HF/LF ratio } 1 \mu \mathrm{Pa} \text { p.p. } \\
(\min / \mathrm{max})\end{array}$ & $\begin{array}{c}\text { Peak freq. } \\
\text { of LF } \\
(\text { std. dev. })\end{array}$ & $\begin{array}{c}-10 \mathrm{~dB} \\
\text { BW }\end{array}$ \\
\hline Freja & 5 & $152(147 / 154)$ & $89(85 / 92)$ & $63 \mathrm{~dB}(58 / 68)$ & $2.3(0.3)$ & $9.5(8.4)$ \\
Sif & 6 & $140(134 / 148)$ & $87(78 / 97)$ & $53 \mathrm{~dB}(48 / 62)$ & $1.8(0.2)$ & $7.0(0.7)$ \\
Eigil & 4 & $141(140 / 144)$ & $81(77 / 84)$ & $62 \mathrm{~dB}(58 / 68)$ & $2.5(0.4)$ & $9.1(3.6)$ \\
\hline \hline
\end{tabular}

cifics at larger ranges. Porpoises must therefore be quite close to acoustically find conspecifics for mating, and mother-calf pairs cannot acoustically stay connected over anything but short separation distances. As long as the population density is high, such short ranges may not be a problem, though it may pose a problem to find conspecifics if the density becomes too low, e.g., due to bycatch mortality (Vinther and Larsen, 2004), possibly prolonging repopulation of low-density areas such as the Baltic Sea (Koschinski, 2002). Second, it is also clear that passive listening devices such as T-pods can only cover ranges out to significantly less than $1 \mathrm{~km}$ given that they have considerably higher detection thresholds (110-120 dB re $1 \mu \mathrm{Pa}_{\mathrm{pp}}$, Kyhn et al., 2007) than the porpoises themselves. Thus, passive acoustic monitoring studies of porpoises must be designed to handle short detection ranges.

\section{Comparing analog to digital recordings of porpoise clicks}

The large amplitude difference of three orders of magnitude between the HF and LF components raises some potential methodological problems in relation to earlier studies using analog tape recorders. The limited dynamic range of the analog tape recorders cannot handle a $+50 \mathrm{~dB}$ difference without clipping the HF component or burying the LF component in noise. Second, the low tape speed used in some studies in combination with the risk of clipping raised our suspicion that the LF components reported from analog recordings at least in some cases could be artifacts created in the recording chain. To investigate if some of the prominent LF components in earlier studies could have been an artifact from clipping or limited tape speed, we used the same Lyrec

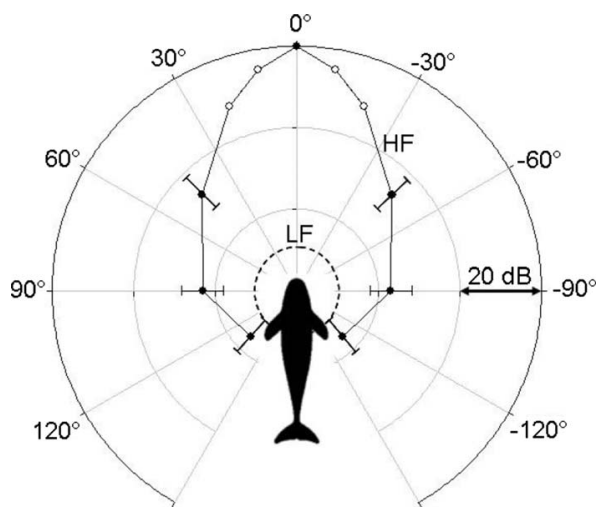

FIG. 4. Measured HF and LF beam pattern (std. dev. $< \pm 5 \mathrm{~dB}$ ). Open data points taken from Au et al. (1999). tape recorder that was used by Mohl and Andersen (1973) to report the first HF components as well as LF components in porpoise clicks.

Several hundred clicks with differing received levels were recorded from free-swimming porpoises. The power spectra of recorded clicks with amplitudes below clipping level did not reveal any LF component in neither the analog nor the digital recordings. However, if the amplitude of a click was above the clipping level of the tape recorder, a distortion appeared, generating significant LF energy in the analog tape recordings that could not be found in the unclipped digital recording of the same clicks. This finding is substantiated by the Wilcoxon signed rank test performed on 13 clicks above clipping level from the tape recorder. The noise residual did not deviate significantly from $0(P=0.8)$ while the signal residual $\operatorname{did}(P=0.0007)$, verifying that it contains a strong LF component in the signal window. Thus, a powerful LF artifact in the same frequency range as the genuine LF component will be generated when clipping the analog tape recorder. This artifact becomes more prominent with the degree of clipping. This finding begs the question if the prominent LF component reported by Schevill et al. (1969), Mohl and Andersen (1973), Amundin (1991a), and Verboom and Kastelein $(1995,1997)$ at least in part could have been created as a result of artifacts from clipping.

\section{E. Recording of artificial porpoise clicks}

To test if the LF content in the clipped signals in the previous experiment was, in fact, generated as an artifact

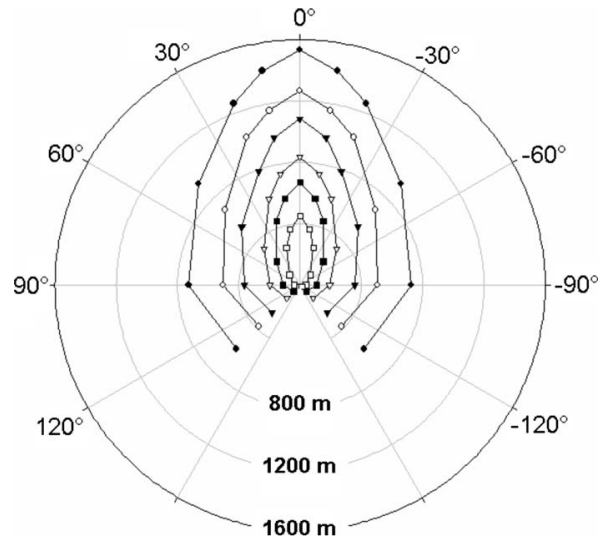

FIG. 5. Estimated detection ranges of porpoises with respect to vocalizing conspecifics based on detection thresholds derived by Kastelein et al. (1999). Circles $=\mathrm{SL}$ of $200 \mathrm{~dB}$ with regard to $1 \mu \mathrm{Pa}_{\text {p.p. }}$, triangles $=\mathrm{SL}$ of $180 \mathrm{~dB}$ with regard to $1 \mu \mathrm{Pa}$, and squares $=\mathrm{SL}$ of $160 \mathrm{~dB}$ with regard to $1 \mu \mathrm{Pa}$. Black and white data points define the aspect of the detecting animal relative to the source. Black: the animal is pointing toward the source; white: the animal is pointing away. 

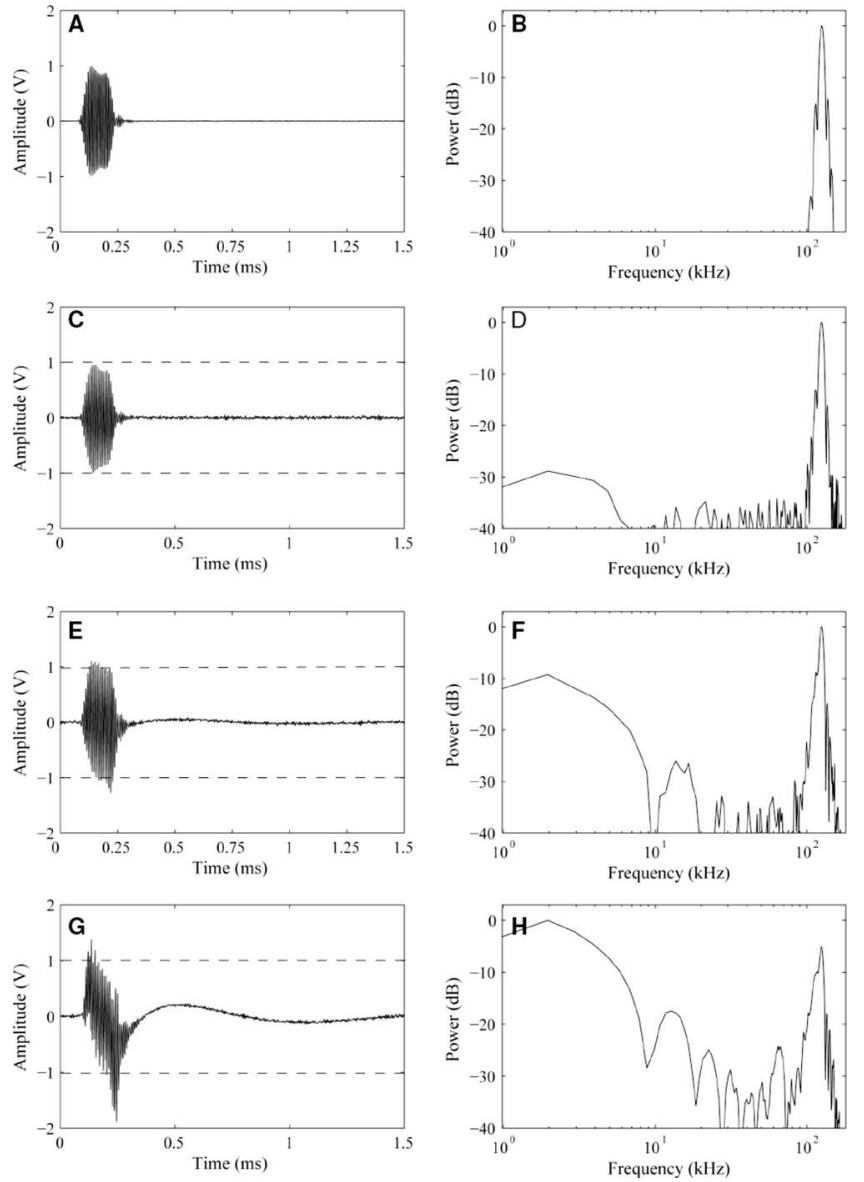

FIG. 6. [(A) and (B)] Waveform and power spectra of the artificial porpoise clicks recorded digitally and $\mathrm{C}-\mathrm{H}$ recorded on the analog Lyrec tape recorder. Clipping level of the tape recorder is indicated by the punctuated lines. In (C) and (D), the input level of the signal was $0 \mathrm{~dB}$ with regard to clipping level of the tape recorder while $(\mathrm{E})$ and $(\mathrm{F})$ was $6 \mathrm{~dB}$ above the clipping level and $(\mathrm{G})$ and $(\mathrm{H}) 12 \mathrm{~dB}$ above the clipping level.

from clipping the analog tape recorder, we repeated the experiment with artificial porpoise clicks with no LF content [Figs. 6(A) and 6(B)]. If LF components appeared in the spectrum, they must have been generated during the recording process. Figure 6(A) presents an artificial porpoise click and its power spectrum [Fig. 6(B)] digitized directly from the signal generation system at $500 \mathrm{kHz}$ sampling rate. When this signal was fed into the tape recorder at a voltage equal to the clipping level $\left(2 \mathrm{~V}_{\mathrm{pp}}\right)$, the signal remains undistorted, and appears very similar to the digitized signal [Fig. 6(C)]. Slightly more LF content is seen in the power spectrum [Fig. 6(D)], but this is due to noise created by the tape recorder during recording and playback with a higher system noise floor (lower dynamic range) than in the digital system. When the input is raised to $4 \mathrm{~V}_{\mathrm{pp}}, 6 \mathrm{~dB}$ above clipping level of the tape recorder, a distorted waveform appears [Fig. 6(E)]. The output amplitude of the analog click is only slightly above the $2 \mathrm{~V}_{\mathrm{pp}}$ that was set as clipping level even though the input was $4 \mathrm{~V}_{\mathrm{pp}}$. In the power spectrum, a distinct LF component appeared in the frequency range from 0.1 to $10 \mathrm{kHz}$, only $10 \mathrm{~dB}$ below the HF component at $125 \mathrm{kHz}$ [Fig. 6(F)]. If the level of the input signal is raised to $8 \mathrm{~V}_{\mathrm{pp}}, 12 \mathrm{~dB}$ above clipping level, the signal becomes heavily distorted [Fig. $6(\mathrm{G})]$ and a very prominent LF component that is more pow- erful than the HF component appears [Fig. 6(H)]. Furthermore, several new frequency components appear in the midfrequency range from 10 to $100 \mathrm{kHz}$. Such LF artifacts are likely the result of rectification of the signal in the preamplifier of the tape recorder creating a dc-voltage component (Weber, 1963), and they start forming even when the clipped waveform appears undistorted [Fig. 6(E)].

The same experiment repeated with a Nagra IV-D tape recorder [mimicking the experiment of Amundin (1991a, 1991b)] revealed similar results except that the Nagra was not able to handle high frequencies at all regardless of whether the signal amplitude was above or below the clipping level of the tape recorder. Heavy distortion of the signal and very powerful LF components appeared at all the tested input levels. We regard that as an artifact of too low tape speed as reported by Diercks et al. (1973), and we infer that parts of the LF components reported in Amundin (1991a, 1991b) could have been created by this phenomenon.

Detection of clipping in an analog tape recorder can be difficult. Unlike digital recordings where clipping is easily identified if it occurs in the ADC, analog recorders smoothen the signal, and clipping becomes apparent only when the signal is heavily distorted. This makes it challenging to distinguish genuine frequency components from artifacts and can lead to erroneous classification of frequency components that are not of biological origin. Our digital recordings, however, are consistent with the LF findings of Mohl and Andersen (1973) who reported the LF component to begin shortly before the HF component. The frequency overlap of genuine and artifactual LF components raises the question of what is genuine and what is an artifact when evaluating reported LF components from studies using analog tape recorders. There is indeed a LF component of around $2 \mathrm{kHz}$ in porpoise clicks (Fig. 3), though it is very weak with a pp amplitude more than $50 \mathrm{~dB}$ below the SL of the HF component. It is therefore hard to conceive how earlier studies using tape recorders with limited dynamic range could have avoided some level of clipping by which the genuine LF component would have been contaminated with stronger LF energy from the DC-like artifact. The present and other recent studies have not been able to reproduce the findings of other frequency peaks at 20, 30 , and $60 \mathrm{kHz}$ reported by Verboom and Kastelein (1995; 1997) and Kamminga and Wiersma (1981). While we cannot exclude that porpoises in some cases can produce midfrequency and LF click components, the most parsimonious explanation would suggest that they are the result of clipping [Fig. 6(H)] and that the classification of porpoise clicks on the basis of different midfrequency components (Verboom and Kastelein, 1995; 1997) is actually based on artifacts from clipping.

\section{CONCLUSIONS}

We have demonstrated that the LF component of porpoise clicks is genuine, though very weak compared to the HF component. The active space of the HF component is larger irrespective of the orientation of the clicking animal with respect to listening conspecifics. That leaves us to conclude that the LF component probably plays no role in har- 
bor porpoise communication. The LF component is more likely generated as a by-product from the pneumatically driven production of the HF component. In fact, the very low SL of the LF component could offer a selective advantage to harbor porpoises and other NBHF toothed whales that may suffer from a higher predation pressure when vocalizing in the hearing range of killer whales (Madsen et al., 2005). Future research on NBHF species and killer whales should test such an assertion through play back experiments. We note that the difference between the HF and LF components of some $50-60 \mathrm{~dB}$ is comparable to the difference between LF and HF components in sperm whale usual clicks, and may therefore reflect a more general relationship for generation of LF by-products.

We have found no results supporting the existence of additional frequency components reported by Verboom and Kastelein (1997) and Kamminga and Wiersma (1981), but we can reproduce them as artifacts by clipping analog tape recorders with the HF component of porpoiselike clicks. The dynamic range of received levels from toothed whale clicks can vary by more than $80 \mathrm{~dB}$ (Madsen and Wahlberg, 2007) depending on directionality of the signal, where the animal is pointing its beam relative to the hydrophone, distance to the hydrophone, and changes in the SL. This put some special demands on the equipment used to record toothed whale echolocation clicks, especially with regard to dynamic range. Recent developments of relatively nonexpensive high-speed digital recording equipment with large dynamic range offer a wide range of advantages compared to the use of analog tape recorders that have been almost completely abandoned (Madsen and Wahlberg, 2007). Nevertheless, it is still important to carefully consider the properties of ultrasonic, highpowered clicks when making recordings to avoid generation of artifacts that can lead to erroneous inferences about the bioacoustics and biology of the species in question.

\section{ACKNOWLEDGMENTS}

B. Mohl, L. A. Miller, and M. Amundin provided access to equipment and gave helpful comments on the experiments and/or on previous versions of the manuscript. K. Beedholm and F. H. Jensen kindly assisted with MATLAB scripts. We thank the trainers and staff at Fjord \& Belt for their help during the experiments. This work was supported by the Carlsberg Foundation and Oticon, and via a Steno Scholarship from the Danish Natural Science Research Council to PTM. All regulations for the use of experimental animals in Denmark were followed.

\footnotetext{
${ }^{1}$ The active space is the range within which a receiver is able to detect the signal (Bradbury and Vehrencamp, 1998).

${ }^{2}$ The few negative sound pressure values can be explained if one of the noise windows subtracted from the signal window by coincidence had a more powerful HF component than the signal window, e.g. from another clicking animal.
}

Amundin, M. (1991a). "Click repetition rate patterns in communicative sounds from the harbour porpoise, Phocoena phocoena," in Sound Production in Odontocetes with Emphasis on the Harbour porpoise, Phocoena phocoena (Swede AB, Stockholm).

Amundin, M. (1991b). "Helium effects on the click frequency-spectrum of the harbor porpoise, Phocoena phocoena," J. Acoust. Soc. Am. 90, 53-59.
Andersen, S., and Amundin, M. (1976). "Possible predator related adaptation of sound production and hearing in the harbour porpoise," Aquat. Mamm. 4, 55-56.

$\mathrm{Au}, \mathrm{W}$. W. L. (1993). The Sonar of Dolphins (Springer, New York).

Au, W. W. L. (1997). "Echolocation in dolphins with a dolphin-bat comparison," Bioacoustics 8.

Au, W. W. L., Kastelein, R. A., Rippe, T., and Schooneman, N. M. (1999).

"Transmission beam pattern and echolocation signals of a harbor porpoise (Phocoena phocoena)," J. Acoust. Soc. Am. 106, 3699-3705.

Bradbury, J. W., and Vehrencamp, S. L. (1998). Principles of Animal Communication (Sinauer Associates, Inc., Sunderland, MA.).

Diercks, K. J., Trochta, R. T., and Evans, W. E. (1973). "Delphinid sonarmeasurement and analysis," J. Acoust. Soc. Am. 54, 200-204.

Dubrovskii, N. A., Krasnov, P. S., and Titov, A. A. (1971). "Emission of echo-location signals by Azov-Sea harbor porpoise," Sov. Phys. Acoust. 16, 444-447.

Dusenbery, D. B. (1992). Sensory Ecology: How Organisms Acquire and Respond to Information (W. H. Freeman and Co, New York).

Fletcher, N. H. (2004). "A simple frequency-scaling rule for animal communication," J. Acoust. Soc. Am. 115, 2334-2338.

Janik, V. M. (2005). "Underwater acoustic communication networks in marine mammals," in Animal Communication Networks, edited by P. K. McGregor (Cambridge University Press, Cambridge).

Kamminga, C., and Wiersma, H. (1981). "Investigations on cetacean sonar II: Acoustical similarities and differences in Odontocete sonar signals," Aquat. Mamm. 8, 41-62.

Kastelein, R. A., Au, W. W. L., Rippe, H. T., and Schooneman, N. M. (1999). "Target detection by an echolocating harbor porpoise (Phocoena phocoena),” J. Acoust. Soc. Am. 105, 2493-2498.

Kastelein, R. A., Bunskoek, P., Hagedoorn, M., Au, W. W. L., and de Haan, D. (2002). "Audiogram of a harbor porpoise (Phocoena phocoena) measured with narrow-band frequency-modulated signals," J. Acoust. Soc. Am. 112, 334-344.

Kastelein, R. A., Verboom, W. C., and de Haan, D. (2005). "Receiving beam patterns in the horizontal plan of a horbor porpoise (Phocoena phocoena)," J. Acoust. Soc. Am. 118, 1172-1179.

Koschinski, S. (2002). "Current knowledge on harbour porpoises (Phocoena phocoena) in the Baltic Sea," Ophelia, Stenstrup, Denmark, 55, 167-197. Lammers, M. O., Au, W. W. L., and Herzing, D. L. (2003). "The broadband social acoustic signaling behavior of spinner and spotted dolphins," J. Acoust. Soc. Am. 114, 1629-1639.

Madsen, P. T., Carder, D. A., Bedholm, K., and Ridgway, S. H. (2005). "Porpoise clicks from a sperm whale nose-Convergent evolution of $130 \mathrm{kHz}$ pulses in toothed whale sonars?," Bioacoustics 15, 195-206.

Madsen, P. T., Payne, R., Kristiansen, N. U., Wahlberg, M., Kerr, I., and Mohl, B. (2002b). "Sperm whale sound production studied with ultrasound time/depth-recording tags," J. Exp. Biol. 205, 1899-1906.

Madsen, P. T., and Wahlberg, M. (2007). "Recording and quantification of ultrasonic echolocation clicks from free-ranging toothed whales," DeepSea Res., Part I 54, 1421-1444.

Madsen, P. T., Wahlberg, M., and Mohl, B. (2002a). "Male sperm whale (Physeter macrocephalus) acoustics in a high-latitude habitat: implications for echolocation and communication," Behav. Ecol. Sociobiol. 53, 31-41.

Mohl, B., and Andersen, S. (1973). "Echolocation-high-frequency component in click of harbor porpoise (Phocoena-Ph. L.), ” J. Acoust. Soc. Am. 54, 1368-1372.

Mohl, B., Wahlberg, M., Madsen, P. T., Heerfordt, A., and Lund, A. (2003). "The monopulsed nature of sperm whale clicks," J. Acoust. Soc. Am. 114, 1143-1154.

Mohl, B., Wahlberg, M., Madsen, P. T., Miller, L. A., and Surlykke, A. (2000). "Sperm whale clicks: Directionality and source level revisited," J. Acoust. Soc. Am. 107, 638-648.

Morisaka, T., and Connor, R. C. (2007). "Predation by killer whales (Orcinus orca) and the evolution of whistle loss and narrow-band high frequency clicks in odontocetes," J. Exp. Biol. 20, 1439-1458.

Piggott, C. L. (1964). "Ambient sea noise at low frequencies in shallow water of Scotian Shelf," J. Acoust. Soc. Am. 36, 2152-2163.

Rasmussen, M. H., Miller, L. A., and Au, W. W. L. (2002). "Source levels of clicks from free-ranging white-beaked dolphins (Lagenorhynchus albirostris Gray 1846) recorded in Icelandic waters," J. Acoust. Soc. Am. 111, 1122-1125.

Schevill, W. E., Watkins, W. A., and Ray, C. (1969). "Click structure in porpoise, Phocoena phocoena," J. Mammal. 50, 721-728.

Szymanski, M. D., Bain, D. E., Kiehl, K., Pennington, S., Wong, S., and 
Henry, K. R. (1999). "Killer whale (Orcinus orca) hearing: Auditory brainstem response and behavioral audiograms," J. Acoust. Soc. Am. 106, 1134-1141.

Teilmann, J., Miller, L. A., Kirketerp, T., Kastelein, R. A., Madsen, P. T., Nielsen, B. K., and Au, W. W. L. (2002). "Characteristics of echolocation signals used by a harbour porpoise (Phocoena phocoena) in a target detection experiment," Aquat. Mamm. 28, 275-284.

Tyack, P. (1998). "Acoustic communication under the sea," in Animal Acoustic Communication. Sound Analysis and Research Methods, edited by S. L. Hopp, M. J. Owren, and C. S. Evans (Springer, New York)

Tyack, P. L., and Clark, C. W. (2000). "Communication and acoustic behavior of dolphins and whales," in Hearing by Whales and Dolphins, edited by W. W. L. Au, A. N. Popper, and R. R. Fay (Springer-Verlag, New York), pp. 156-224.

Urick, R. J. (1983). Principles of Underwater Sound (McGraw-Hill, New York).

Verboom, W. C., and Kastelein, R. A. (1995). "Acoustic signals by harbour porpoises (Phocoena phocoena)," in Harbour porpoises-Laboratory Stud- ies to Reduce Bycatch, edited by P. E. Nachtigall, J. Lien, W. W. L. Au, and A. Read (De Spil, Woerden), pp. 1-39.

Villadsgaard, A., Wahlberg, M., and Tougaard, J. (2006). "Echolocation signals of wild harbour porpoises, Phocoena phocoena," J. Exp. Biol. 210, 56-64.

Vinther, M., and Larsen, F. (2004). "Updated estimates of harbour porpoise (Phocoena phocoena) bycatch in the Danish North Sea bottom-set gillnet fishery," J. Cetacean Res. Manage. 6, 19-24.

Weber, P. J. (1963). The Tape Recorder as an Instrumentation Device (Ampex Corporation).

Zimmer, W. M. X., Madsen, P. T., Teloni, V., Johnson, M. P., and Tyack, P. L. (2005a). "Off-axis effects on the multipulse structure of sperm whale usual clicks with implications for sound production," J. Acoust. Soc. Am. 118, 3337-3345.

Zimmer, W. M. X., Tyack, P. L., Johnson, M. P., and Madsen, P. T. (2005b). "Three-dimensional beam pattern of regular sperm whale clicks confirms bent-horn hypothesis," J. Acoust. Soc. Am. 117, 1473-1485. 